\title{
A Ticking Noise From the Chest: Recognition of the Hamman Sign
}

Nicole Wijnen, MD; Yannick Groutars, MD; Joep Thijssen, MD, PhD

\section{The authors describe a case of a 21-year-old woman who presented with shortness of breath and exhibited a Hamman sign, an uncommon clinical finding.}

raditionally, a physician develops a differential diagnosis based primarily $(>70 \%)$
on the history and the physical examination of a patient. ${ }^{1}$ While modern medicine
has developed with new technological devices and a growing number of diagnos-
tic tests, one must not forget the value of a thorough physical examination.

Case

A 21-year-old woman, in previous good health, presented to the ED with the chief complaint of shortness of breath. She stated that she woke up with acute dyspnea and a stabbing pain on the left side of her thorax, related to her breathing. The patient looked distressed upon presentation.

Her vital signs at presentation were: blood pressure, 150/85 mm Hg; heart rate, 120 beats/min; respiratory rate, 22 breaths/min; and temperature, $100.6^{\circ} \mathrm{F}$. Oxygen saturation was $100 \%$ on room air.

During physical examination, a loud ticking noise was heard originating from the thorax, even without a stethoscope (an example of the sound can be heard at https://www.youtube.com/watch?v=mXJHtJeL1mM). During auscultation, the ticking noise was prominent in early systole and audible over all parts of the thorax. The sound was only heard when the patient was in the supine position and disappeared when she sat up. It persisted when the patient was holding her breath. Breath sounds were equal and clear bilaterally. There was no subcutaneous emphysema palpable over the thorax or neck region.

The electrocardiogram and blood results, including D-dimer, were normal. The chest $\mathrm{X}$-ray showed an apical pneumothorax of $1.5 \mathrm{~cm}$ on the left side (Figures 1 and 2). There was no evidence of pneumomediastinum or pneumopericardium. The patient received acetaminophen and ibuprofen tablets for pain, and she was discharged home. At the follow-up 2 weeks later, she had no remaining symptoms and the ticking sound had disappeared.

\footnotetext{
Dr Wijnen is a resident, department of emergency medicine, Leids Universitair Medisch Centrum, Leiden, Netherlands. Dr Groutars is an emergency physician, Leids Universitair Medisch Centrum, Leiden, Netherlands. Dr Thijssen is a cardiologist, Leids Universitair Medisch Centrum, Leiden, Netherlands.
}

Authors' Disclosure Statement: The authors report no actual or potential conflict of interest in relation to this article.

DOI: 10.12788/emed.2018.0107 


\section{Discussion}

These loud intermittent noises originating from the thorax were described for the first time at the beginning of the 19th century. ${ }^{2,3}$ However, it was Louis Virgil Hamman whose name would be linked to this physical examination finding. In 1937 he described typical clicking, crackling, and popping sounds over the precordium, synchronized with the heartbeat. This was usually in combination with subcutaneous emphysema in the neck region. Hamman presumed that the symptoms were due to mediastinal air caused by rupture alveoli or bronchioles, resulting in interstitial emphysema of the lung parenchyma. In addition, air could leak into the pleural space, causing a pneumothorax. He concluded that the clinical findings were pathognomonic for spontaneous mediastinal emphysema, and this physical examination finding became known as the "Hamman sign". ${ }^{4-11}$

However, in the following years it was demonstrated that the appearance of loud, systolic clicking noises over the precordium could also be present in patients with a small spontaneous left-sided pneumothorax..$^{5-9}$ It was assumed the pneumothorax caused a small amount of air to accumulate in the pleural space in the major fissure inferiorly, which shifted with the cardiac contraction. This results in the noise being present while in the supine position. In the sitting position, the air moves cranially above the heart, meaning it is not influenced by the cardiac contractions and the noise disappears. ${ }^{5-8}$ The Hamman sign is absent in right-sided pneumothorax, presumably because of the smaller contact surface between the lung pleura and the mediastinal pleura overlying the heart in comparison to the left side. Also, the contractions of the right side of the heart are much weaker and generate less pressure in comparison to the left atrium and ventricle..$^{8,11}$

Only a small amount of air, approximately $25 \mathrm{~mL}$, is enough to produce the typical sound. In larger pneumothorax's, with more than $125 \mathrm{~mL}$ of intrapleural air, these sounds are absent, because the contractions of the heart cannot create enough pressure to cause the accumulated air to shift in the pleural space. ${ }^{5,8-9}$

Sound analysis in left-sided pneumothorax by Roelandt et $\mathrm{al}^{7}$ showed multiple murmurs which can be present in both systole and diastole. In contrast to pulmonic noises,

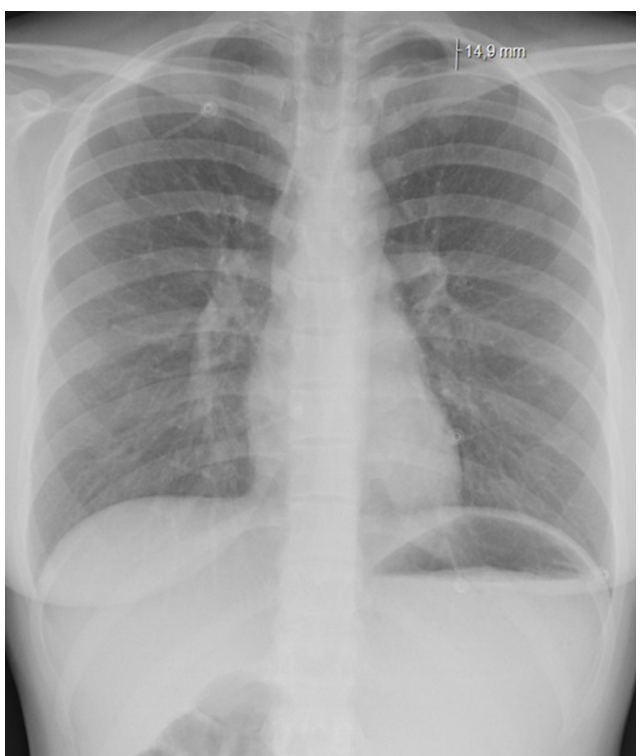

Figure 1. X-ray of thorax, anteroposterior view. A small left sided pneumothorax of $14.9 \mathrm{~mm}$ is seen.

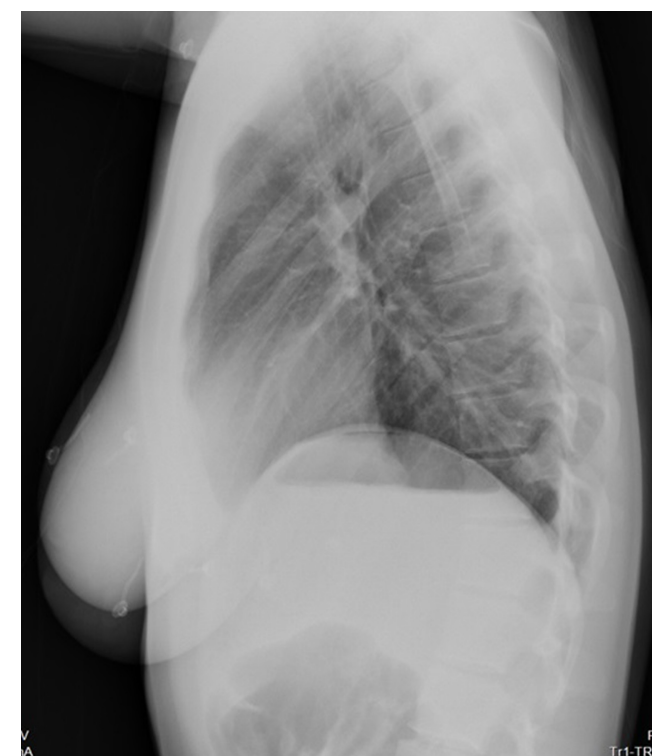

Figure 2. X-ray of thorax, lateral view. 
the Hamman sign persists when the patient is holding their breath and disappears with sitting or standing..$^{3,6-10}$ Furthermore, it must not be confused with extra heart sounds, which present as a "gallop rhythm", with a strong resemblance in quality to the first normal heart sound (S1). In addition, extra heart sounds are uncommon in healthy patients and do not appear suddenly or temporarily. ${ }^{5,8}$

The Hamman sign is a rare physical examination finding, only identified in less than $1 \%$ of all patients with a pneumothorax. ${ }^{9}$ However, its presence is so specific that it is strong evidence for an underlying pneumothorax or pneumomediastinum, even if radiographic imaging is normal. ${ }^{10}$ As previously stated, since the Hamman sign is mostly commonly associated with a pneumothorax consisting of less than $125 \mathrm{~mL}$ of air, these can usually be treated conservatively, without the necessity of placing a chest tube or aspiration. However, when a patient experiences significant shortness of breath, the emergency physician should consider ordering additional imaging, in the form of an ultrasound or a computed tomography scan to identify the underlying cause of the Hamman sign and place a chest tube when clinically indicated.

\section{Conclusion}

The Hamman sign is a rare clinical examination finding in left-sided pneumothorax or pneumomediastinum, in which a ticking or crackling noise is heard over the thorax. This is mostly synchronous with the heartbeat and not related to respiration. It is caused by a small amount of accumulated air in the pleural space, which is being displaced by cardiac contractions during the cardiac cycle. Although typically small, pneumothoraces have a good prognosis. Recognition of the Hamman sign is important, and physicians must realize that even a normal chest X-ray does not rule out the diagnosis.

\section{References}

1. Sandler G. Costs of unnecessary tests. Br Med J. 1979;2(6181):21-24.

2. Laennec RTH, Andral G, Laennec M. Traité De L'auscultation Médiate, Et Des Maladies Des Poumons Et Du Coeur. Paris, France: Paris, J.S.Chaudé, 1826; 1837.

3. Lister WA, Camb MB, Lond MRCP. A case of pericardial knock associated with spontaneous pneumothorax. Lancet. 1928;211(5468):1225-1226.

4. Hamman L. Spontaneous interstitial emphysema of the lungs. Tr A Am Physicians. 1937;52:311-319.

5. Scadding JG, Lond MRCP, Wood P. Systolic clicks due to left-sided pneumothorax. Lancet. 1939;234(6067):12081211.

6. Scott JT. Mediastinal emphysema and left pneumothorax. Dist Chest. 1957;32(4):421-434.

7. Roelandt J, Willems J, van der Hauwaert LG, de Geest H. Clicks and sounds (whoops) in left-sided pneumothorax. Clinical and phonocardiographic study. Dis Chest. 1969;56(1):31-36.

8. Smit FW, van Embden Andresen GH, Ubbens R. "Hammans's sign”, pneumomediastinum and pneumothorax. Ned Tijdschr Geneeskd. 1974;118(22):828-833.

9. Baumann MH, Sahn SA. Hamman's sign revisited. Pneumothorax or pneumomediastinum? Chest. 1992;102(4):1281-1282.

10. Remmelts HH, Banga JD. Popping pneumothorax. Neth J Med. 2010;68(4):187.

11. Jaiganesh T, Wright K, Sadana A. Mobile diagnosis: Hamman's crunch in a primary spontaneous pneumothorax. Emerg Med J. 2010;27(6):482-483. doi:10.1136/emj.2009.079681. 